\title{
Effect of Pulse Jet MQL in Surface Milling of Hardened Steel
}

\author{
Mahmood Al Bashir ${ }^{1 *}$, Mozammel Mia ${ }^{1}$ and Nikhil Ranjan Dhar ${ }^{2}$ \\ ${ }^{1}$ Department of Mechanical and Production Engineering \\ Ahsanullah University of Science and Technology, Dhaka-1208, Bangladesh \\ ${ }^{2}$ Department of Industrial and Production Engineering, \\ Bangladesh University of Engineering and Technology, Dhaka-1000, Bangladesh \\ *Corresponding email: arif_ipe@yahoo.com
}

\begin{abstract}
Minimum quantity lubricant (MQL) machining is an emerging cooling technology that ensures green machining. In this research work, an innovative design for the application of $M Q L$ in the form of pulse jet was created, following the development of that applicator. The surface milling of AISI 4140 steel, heat treated to $40 \mathrm{HRC}$, was investigated with pulse jet minimum quantity lubricant applicator using VG-68 grade straight cut cutting oil as the cutting fluid in respect of cutting force, surface roughness and tool flank wear with machining time. Four flute carbide end mill cutter was used to investigate the change in tool wear, and compared with that of the dry condition. The result and analysis indicate that this pulse jet MQL applicator can be utilized in hard milling operation to ensure better surface finish and minimal tool wear and cutting force.
\end{abstract}

Keywords: $M Q L$, pulse jet, hardened steel, surface milling, cutting force, tool wear, roughness

\section{INTRODUCTION}

Machining plays important role in producing product from different types of material ranging from soft to hard. Bringing a hardened part to machine traditionally has been slow and time consuming. The traditional approach is to rough and semi finish parts before hardening via heat treatment if possible, then tediously finish them with round tools, inserts, grinding or EDM Machining. Long cycle times, multiple operations and part setups and excessive work-in-process, all adhered up to increase the manufacturing costs. Moreover, dimensional accuracy, tool wear and quality of surface finish are three factors that manufacturers must be able to control at the machining operations to ensure better performances and service life of engineering component. Use of cutting fluid has been a common practice in manufacturing industries to reduce the heat, facilitate chip removal and lubrication process. But use of coolants also require additional cost that eventually boosts up the total manufacturing cost due to cutting fluid's purchase, usage, storage and disposal. The increased use of cutting fluids in the traditional machining industries also creates health hazards for the operators as well as the environment. A number of studies have shown that the mist that is generated from the use of cutting fluid on the heated surface of the machined material creates a number of health problems for the operator and people working in the proximity ${ }^{1}$. Based on these facts an alternate approach to reduce the usage of cutting fluid has been long in the focus of the industries. Cutting forces, cutting temperature, chip tool interaction, dimensional accuracy, surface integrity and quality, chip morphology, wear and life of the cutting tool in different cutting conditions are the main concerns in the research and investigation done so far on different types of machining operations. While lubrication is necessary in controlling friction and by consequence the heat generation, more cooling is required in cases where heat generation considerably affects the machining quality, and where more temperature control is needed. These high temperatures are due to the fact that nearly all work done in a machining process is transformed into heat. A major portion of the energy is consumed in the formation and removal of chips. The greater the energy consumption, the greater the temperature and the frictional force at the tool-chip interface and consequently the higher is the tool wear. For this reason, conventional coolant is often used on the cutting tool to prevent overheating. However, the main problem with conventional coolant is that it does not reach the real cutting area ${ }^{2}$. Moreover because of having high temperature conventional cutting fluids evaporates before reaching the cutting zone $\mathrm{s}^{3}$. Hence, heat generated during machining is not removed and is one of the main causes of the reduction in tool life ${ }^{4}$.

The conventional coolant method as based on a flooding system is not always effective as the coolant often fails to penetrate into the tool chip interface during the machining process 5 . Metal cutting fluids changes the performance of machining operations because of their lubrication, cooling, and chip flushing functions. Typically, in the machining of hardened steel materials, no cutting fluid is applied in the interest of low cutting forces and low environmental impacts. MQL presents itself as a viable alternative for hard machining with respect to tool wear, heat dissertation, and machined surface quality. MQL, also known as "Micro-lubrication", and "Near-Dry Machining"7, is the latest technique of delivering metal cutting fluid to the tool/work interface. Using this technology, a little fluid, when properly selected and applied, can make a substantial difference in how effectively a tool performs. In conventional operations utilizing flood coolant, cutting fluids are selected mainly on the basis of their contributions to cutting 
performance. In MQL however, secondary characteristics are important. These include their safety properties, biodegradability, oxidation, and storage stability. This is important because the lubricant must be compatible with the environment and resistant to long term usage caused by low consumption $^{8}$. In MQL, lubrication is obtained via the lubricant, while a minimum cooling action is achieved by the pressurized air that reaches the tool/work interface. Further, MQL reduces induced thermal shock and helps to increase the workpiece surface integrity in situations of high tool pressure ${ }^{9}$. Ronan et al. ${ }^{10}$ compared the mechanical performance of minimum quantity lubrication to completely dry lubrication for the turning of hardened bearing-grade steel materials based on experimental measurement of cutting forces, tool temperature, white layer depth, and part finish. The results indicate that the use of minimum quantity lubrication leads to reduced surface roughness, delayed tool flank wear, and lower cutting temperature, while also having a minimal effect on the cutting forces.

Varadarajan et al. ${ }^{11}$ have introduced a new MQL application technique which overcomes the problems caused by mist. In this method, small quantities of cutting fluid were applied in the form of high velocity, narrow, pulsed jet. The amount of cutting fluid used was only $2 \mathrm{ml} / \mathrm{min}$. The performance in hard turning of hardened tool steel during minimal cutting fluid application was superior to that during dry turning and conventional flood turning on the basis of cutting force, tool life, surface finish, cutting ratio, cutting temperature and tool-chip contact length. Khan et al. ${ }^{12}$ applied external vegetable oil MQL in turning of steel (AISI 9130) using an uncoated carbide inserts. Tests were conducted with a $1 \mathrm{~mm}$ depth of cut at cutting speeds between 223 and $483 \mathrm{~m} / \mathrm{min}$ and feed rates in the range of 0.1 to $0.18 \mathrm{~mm} / \mathrm{rev}$. The pure oil MQL flow rate was $100 \mathrm{ml} / \mathrm{h}$ with an air pressure of 6 bars. The performance of MQL was compared with that of dry machining and flood cooling at a rate of $360 \mathrm{l} / \mathrm{h}$. It was found that MQL provided a $10 \%$ reduction of temperatures compared to flood cooling. This effect was more prominent at higher speeds, producing smoother and brighter chips and preventing any BUE formation. Minimum quantity lubrication technique reduces the amount of consumption of cutting fluid at a considerable amount. Along with that, the MQL system facilitates drastic reduction in the tool chip interaction. This leads to reduction in cutting force which decreases the tool wear. Reduced tool-chip and tool-work interactions also lead to lower thermal distortion and tool wear. This leads to improvement in surface finish and dimensional accuracy ${ }^{13}$.

In end-milling, the cutting is performed at the tip as well as the sides of the end-mill, thus the lubrication system must supply all these areas if adequate lubrication is necessary. Yan et al. ${ }^{14}$ investigated the significance of the MQL injection parameters on the milling of 50CrMnMo steel. Tests were conducted at a cutting speed of $220 \mathrm{~m} / \mathrm{min}$ and a feed of $0.14 \mathrm{~mm} /$ tooth. The axial depth of cut used was $0.5 \mathrm{~mm}$, and the radial depth of cut was $8 \mathrm{~mm}$. The oil flow rate was varied between 13.9 and 58.4 $\mathrm{ml} / \mathrm{h}$, and the air pressure was varied between 2 and 6 bar. Within this range, the change in oil flow rate had negligible effects on flank wear, except at the lower levels. The increase in air flow rate led to a reduction in tool wear, reportedly due to better chip removal and the improved penetration of the flow to the cutting zone. Comparison of MQL with dry and flood cooling conditions showed that MQL produced the lowest tool flank wear and average roughness of the machined surface.

Hwang et al. $^{15}$ evaluated the machinability of aluminum (A16061) in milling tests using MQL (vegetable oil) and flood as the mode of lubrication. Analysis of Variance (ANOVA) was used to evaluate the importance of the different parameters on the surface roughness and cutting forces. The MQL supply was efficient in reducing the tool adhesion levels, which was the main wear mechanism, and was strongly dependent on the coolant supply method. MQL led to significantly longer tool life, particularly at higher speeds, while flood cooling was ineffective even when compared to dry cutting. The use of MQL also resulted in lower levels of thermal cracking in the tool, compared to flood and dry machining, due to the lower temperature gradients which were significant in the case of flood cooling. The lower tool wear rate in the case of MQL also had a strong impact on reducing the cutting forces.

The objectives of the present work was the designing and development of a pulsed jet MQL applicator and a comparative study of MQL by pulsed jet and dry condition in respects of the progression of the surface roughness, tool wear and cutting force with machining time in machining hardened AISI 4140 steel at specific cutting speed, feed and depth of cut.

\section{PULSE JET APPLICATOR}

\section{Full factorial analysis of MQL applicator}

A total of nine variables, considered valuable for a good design, of the applicator are collected and listed below.

1. Container size, material and sealing

2. Volume of the container

3. Height of the container

4. RPM of the motor running the fuel pump

5. Number of nozzles of the fuel pump

6. Diameter of the nozzle injector

7. Milling cutter, type and material

8. Pressure and flow of the cutting fluid

9. Angle of the spray pattern

After a long and perceptive brain storming the following four factors, shown in Table-1, are 
considered vulnerable for the optimized performance of the applicator.

Table-1: Factors of critical importance.

\begin{tabular}{llll}
\hline \multirow{2}{*}{$\begin{array}{l}\text { Sym } \\
\text { bol }\end{array}$} & Factors & \multicolumn{2}{c}{ Level (+/-) } \\
\cline { 2 - 4 } & & Present (-) & Exp. $(+)$ \\
\hline A & Dia. of nozzle injector & $1 \mathrm{~mm}$ & $0.5 \mathrm{~mm}$ \\
B & Volume of container & $250 \mathrm{cc}$ & $100 \mathrm{cc}$ \\
C & Angle of spray pattern & $60^{\circ}$ & $30^{\circ}$ \\
D & Pulsing frequency & 1450 & 800 \\
\hline
\end{tabular}

Due to the time and resource constraint only 8 runs were taken and the surface roughness was recorded. Preliminary experiments were conducted using a single jet configuration to find out the viability of MQL application for hard milling and to find a set of fluid application parameters that can provide minimum surface roughness. The $p$-value and f-value of the variables are as shown in Table-2.

\section{Fabrication and Testing}

The fuel pump accommodates a plunger, embedded with helical groove, which can rotate about its axis, and the degree of rotation of the plunger presets the quantity of fluid, facilitating accurate quantity control by plunger rotation, delivered per stroke. The plunger reciprocation, eventuated by AC motor rotation, delivers one pulse of cutting fluid for each revolution through the fluid injector. Although the fluid flow alternates in four outlets, three of the outlets were sealed; securing one outlet connection with the nozzle injector.

\begin{tabular}{lll}
\hline \multicolumn{3}{l}{ Table-2: F-value and P-value from ANOVA } \\
\hline Symbol & F-value & P-value \\
\hline A & 0.02 & 0.901 \\
B & 3.05 & 0.131 \\
C & 0.15 & 0.708 \\
D & 3.05 & 0.131 \\
\hline
\end{tabular}

Speed regulator, used to provide variable speed of the motor, controls the pulsing frequency and amount of cutting fluid. The experimental setup facilitates independent variation of frequency of pulsing and rate of fluid application. The container, placed above the fuel pump, provides continuous supply of VG-68 grade cutting oil. The nozzle injector, attached with the outlet of the fuel pump by means of a semi flexible channel, uses the channel to get closer to the milling cutter during the machining process. A schematic block diagram showing the pulse jet application is shown in Fig.1.

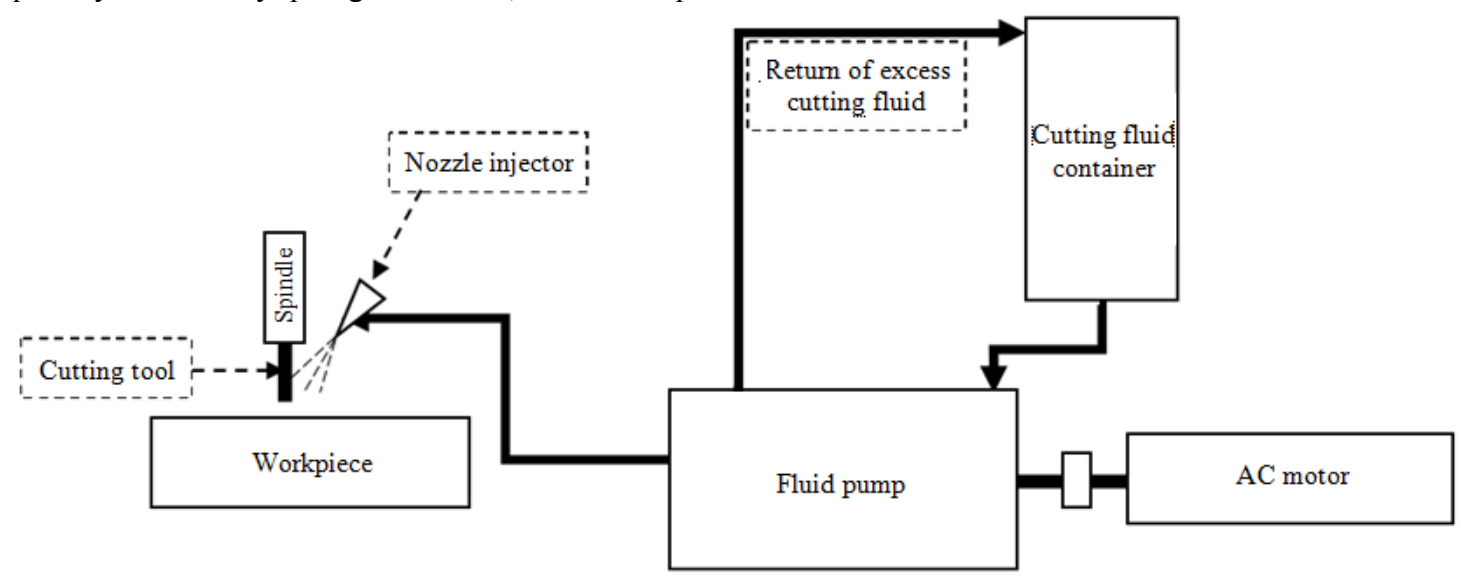

Figure1. Schematic view of pulsed jet application.

The nozzle injector delivers cutting fluid at single pulse per revolution. This facilitates the application of a minute amount of cutting fluid to be used per pulse during the machining process. Pulsing jet aids in fluid minimization without compromising the velocity of individual particles as the pressure at the fluid injector remains constant at the set value. The fluid delivery amount is controlled, if other factors remain constant, by the pulse variation.

Two different nozzle injectors, varied by spray angle at $30^{\circ}$ and $60^{\circ}$, were used to test the setup and find the minimum surface roughness during the experiment. The spray angle does not remain constant as spray length increases. To conform to the continuity of the flow rate the nozzle injector was tested at sample runs and the repeatability of the system was plotted as shown in Fig.2. From the plot, shown in Fig.2, it is seen that the repeatibilty of the process is good as the variation of the flow rate are within the range of $75 \pm 1 \mathrm{ml} / \mathrm{hr}$ along the number of tests which ensures the consistency of the flow rate during the experiment.

A number of factors are responsible to determine the nozzle diameter as well as the spray angle of the nozzle injector. Depending on the flow rate and fluid type the nozzle diameter and spray pattern varies. Liquids, more viscous than water, form smaller spray angles, or solid streams, depending upon nozzle capacity, spray pressure, and viscosity. Drop size increases with the decrease in spray pattern and high pressure process streams force narrower spray angles. To achieve a wide spray angle normally low pressure 
streams are used. As illustrated in the Fig.3, the spray angle tends to collapse or diverge with increasing distance from the orifice. Spray coverage varies with spray angle. The spray angle is assumed to remain constant throughout the entire spray distance.

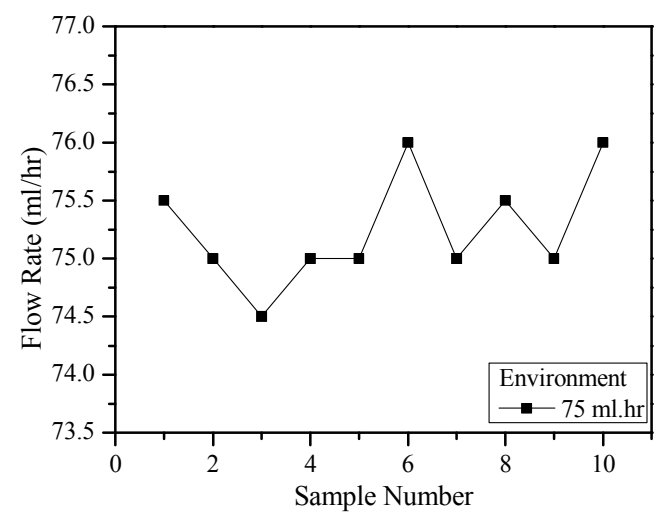

Figure 2. Repeatability check of the MQL applicator for $75 \mathrm{ml} / \mathrm{hr}$ flow rate.

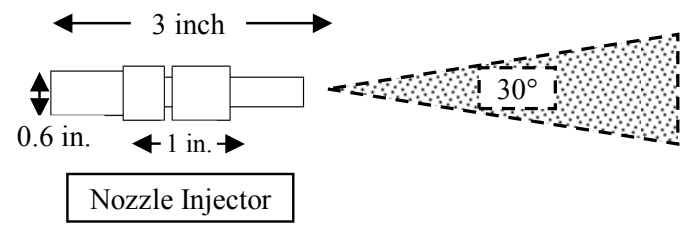

\section{MACHINES AND EQUIPMENTS}

The machining test has been carried out by milling of AISI 4140 steel, hardened to $40 \mathrm{HRC}$ by heat treatment, in a column and knee type vertical milling machine ( $7.5 \mathrm{hp}$, China) by four flute carbide milling cutter at different cutting velocities and feeds under dry and MQL cutting condition. The heat treatment process was conducted in the sequence of austenizing i.e. heating the workpiece to $900^{\circ} \mathrm{C}$ and holding there for $90 \mathrm{~min}$, quenching i.e. sudden temperature reduction to $30^{\circ} \mathrm{C}$ using gluta oil, and tempering i.e. further increase of temperature to $300^{\circ} \mathrm{C}$ and cooling in still air. The conditions under which the machining tests have been carried out are briefly summarized in Table-3. Carbide end mill cutter (Ø12 mm), possessing helical positive cutting edges with straight shank, was used in the investigation. The width of the flank wear was measured using metallurgical microscope (Carl Zeiss, Germany) fitted with micrometer of $1 \mu \mathrm{m}$ resolution. The surface roughness of the machined surface after each operation was measured by a Talysurf roughness checker (Surtronic $3^{+}$, Rank Hobson, UK) using a sampling length of 0.8 mm. A dynamometer, load cell type with charge amplifier, was used to measure the cutting force. The machining set up is shown in Fig.4.

Figure 3. Schematic view of spray pattern.

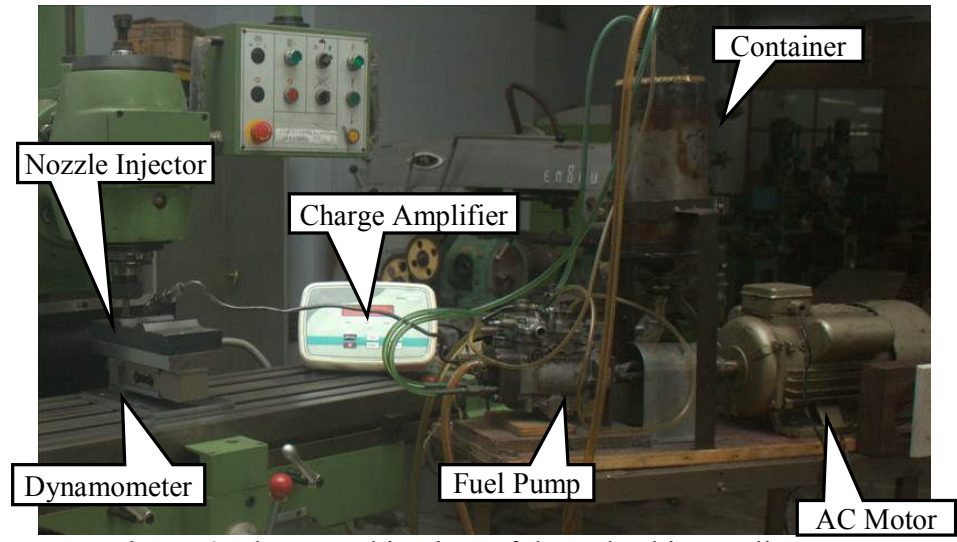

Figure 4. Photographic view of the pulsed jet applicator.

Table-3 Experimental conditions

\begin{tabular}{ll}
\hline Machine Tool & $\begin{array}{l}\text { : Vertical Knee and Column type } \\
\text { Milling Machine, China }\end{array}$ \\
Work Materials & $:$ AISI 4140 Hardened steel \\
Hardness & $:$ 40 HRC \\
Cutting Tool & $:$ Carbide End Milling Cutter \\
Process Parameters & \\
$\quad$ Cutting speed (V) & $: 32 \mathrm{~m} / \mathrm{min}$ \\
$\quad$ Table feed (f) & $: 68 \mathrm{~mm} / \mathrm{min}$ \\
$\quad$ Depth of cut (t) & $: 1.50 \mathrm{~mm}$ \\
Cutting Fluid & $:$ VG 68 Straight cut cutting oil \\
Environment & $:$ Dry and MQL \\
MQL Flow rate & $: 75 \mathrm{ml} / \mathrm{hr}$ \\
\hline
\end{tabular}

\section{DISCUSSIONS ON RESULTS}

Cutting tool wear is a critical phenomenon during machining process. During milling, the cutting tool generally fails by abrasion, adhesion, diffusion, chemical erosion etc. depending upon the tool-work materials and milling conditions. The wear of cutting tools initiates with a faster rate, commonly known as break-in-wear, which is caused by micro chipping at the sharp cutting edge. Premature fail often occurs by mechanical breakage and plastic deformation under adverse milling conditions. However, in the present investigations with the cutter and work material and 
the milling conditions undertaken, the tool failure mode has been mostly gradual wear. The growth of flank wear of the four flute end mill cutter has been measured with the progress of machining time. The growth of flank wear attained after preset intervals of milling at a specific cutting speed and table feed combination under dry and MQL conditions are shown in Fig.5.

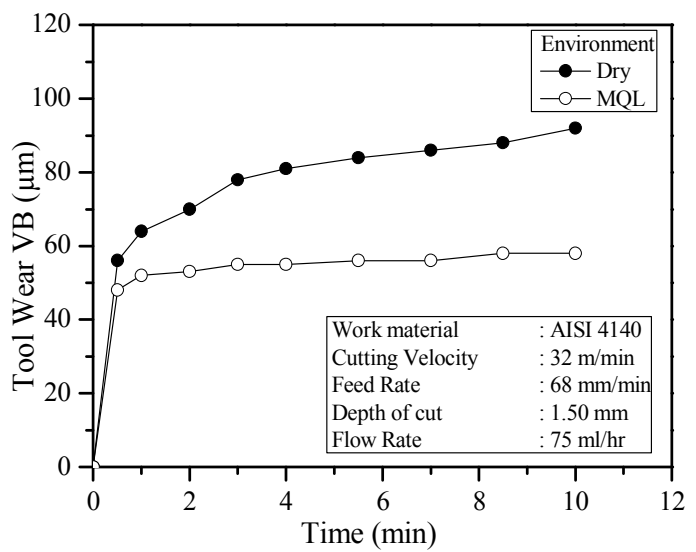

Figure 5. Growth of tool wear with time under dry and MQL condition.

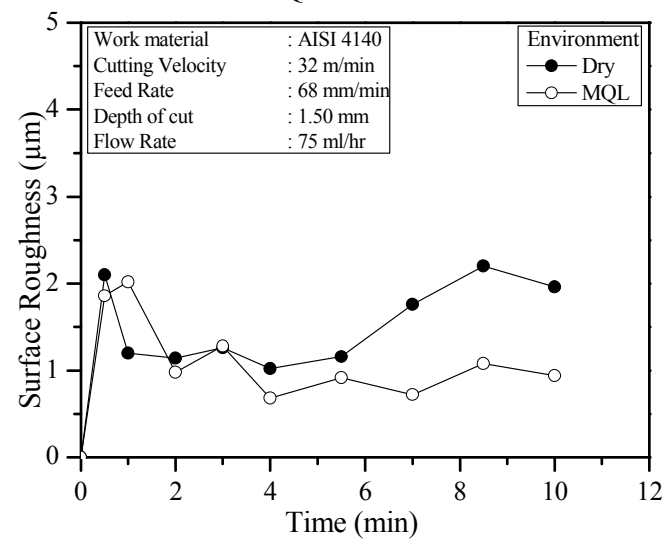

Figure 6. Variation of surface roughness with time under dry and MQL condition.

The growth of flank wear, as shown in Fig.5, reflects a clear divergence between dry and MQL condition, with the progress of machining time. It is also manifested that application of MQL reduces tool wear and its rate of progression. This can be attributed to the retention of hardness and sharpness of the cutting edge of the four flute end mill cutter because of the precise cooling at the chip tool interface, protecting the newly formed fresh material surface from oxidation and corrosion.

Surface roughness indicates the state of a machined surface. The shape and size of irregularities on a machined surface have a major impact on the quality and performance of that surface, and on the performance of the end product. Measurement of surface roughness is necessary to maintain high product performance. Surface integrity, in turn depends on surface roughness, oxidation, corrosion, residual stresses and surface and subsurface micro-cracks.

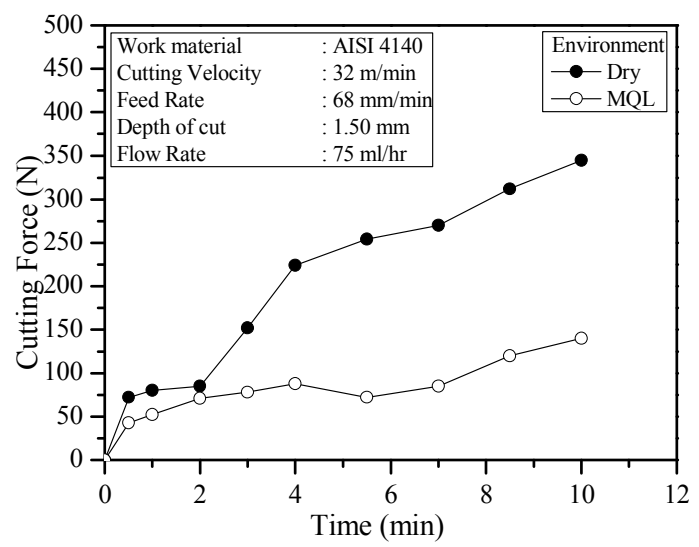

Figure 7. Variation of cutting force with time under dry and MQL condition.

Figure 6 illustrates the variation of surface roughness, both dry and MQL machining, with the progression of machining time. The pattern, plotted in Fig.6, divulges initial rise in surface roughness followed by gradual decrease and an eventual increase. Although, one fact is clear that the MQL application produces better surface. This phenomenon can be addressed by the application of pulse jet MQL. Since, the fluid pulse is employed at certain intervals, and the lubrication and cooling are dependent on it, the roughness is varied accordingly.

Cutting force, along with other parameters attribute to the product quality, functionality and machining cost. Cutting force increases with the increase of the material strength, shear strength to be specific. Increase in the cutting force during machining is always detrimental as it decreases the tool life and increases the surface roughness. Variation of cutting force with machining time is shown, for both dry and MQL condition, in Fig.7.

At the start of machining the cutting force is very low as the tool retains its sharpness and strength. But with the increase of machining time the generated cutting force increases rapidly in case of dry machining as the tool starts to lose the sharpness and faces severe tool wear as illustrated in Fig.5. However, MQL assisted machining confers different perspective, little variation with low average cutting force and maintain significant difference with dry machining.

It is evident from Fig. 5 and Fig. 6 that tool wear and surface roughness tends to improve with MQL condition than that of dry condition. With the increase of machining time tool wear increased steadily to 56 $\mu \mathrm{m}$ in MQL cutting condition. But during the dry milling the tool wear was found to be around $90 \mu \mathrm{m}$ 
with the increase in machining time. This increase of tool wear can be attributed to the increase in surface roughness in both MQL and dry milling condition. From Fig. 6 it can be seen that in both the cases the surface roughness reached a peak level initially and after that gradually increased. It can also be inferred that the degree of increase in surface roughness varies in MQL and dry milling condition. It is evident from Fig. 6 that MQL improves the surface roughness than that of dry milling in a substantial amount. The Fig.7 shows substantial improvement in cutting force generation by MQL, which otherwise, would cause severe vibration, sudden tool break and rough surface generation.

\section{CONCLUSIONS}

A systematic and innovative approach has been utilized, following design for manufacturing and assembly guidelines, to fabricate an efficient and consistent pulse jet minimum quantity lubricant applicator. Later, this developed applicator is appointed in the investigation of cutting force, tool wear and surface roughness during surface milling. The key findings include:

- Both tool wear and cutting force increases with the increase in machining time. All things being equal, the pulse jet MQL was found to offer better tool performance and reduced cutting force.

- Maximum tool wear and cutting force reduction are $37 \%$ and $68.5 \%$ respectively due to application of MQL compared to dry machining.

- Cutting force, if other things are constant, seems to be dependent on tool wear as the tool sharpness and strength affect force generation.

- The workpiece roughness values obtained in dry machining is very high compared to that of MQL assisted machining. In addition, maximum roughness reduction by MQL is $59 \%$.

\section{ACKNOWLEDGEMENT}

The authors would like to acknowledge the financial support provided by Directorate of Advisory Extension and Research Services, BUET, and technical support provided by Department of Industrial and Production Engineering and Department of Materials \& Metallurgical Engineering, BUET, Dhaka, Bangladesh.

\section{REFERENCES}

1.Ding, Y.; Hong, S., Improvement of chip breaking in machining low carbon steel by cryogenically precooling the workpiece. Journal of manufacturing science and engineering 1998, 120 (1), 76-83.

2.Werthem, R.; Rotberg, J., Influence of high pressure flushing through the rake face of the tool. Annals CIRP 1992, 41 (1), 101-106.
3.Kamruzzaman, M.; Dhar, N., The influence of high pressure coolant on temperature tool wear and surface finish in turning $17 \mathrm{CrNiMo6}$ and $42 \mathrm{CrMo} 4$ steels. Journal of Engineering and Applied Sciences 2009, 4 (6), 93-103.

4.Kumar, A. S.; Rahman, M.; Ng, S., Effect of highpressure coolant on machining performance. The International Journal of Advanced Manufacturing Technology 2002, 20 (2), 83-91.

5.Paul, S.; Dhar, N.; Chattopadhyay, A., Beneficial effects of cryogenic cooling over dry and wet machining on tool wear and surface finish in turning AISI 1060 steel. Journal of Materials Processing Technology 2001, 116 (1), 44-48.

6.MaClure, T.; Adams, R.; Gugger, M., Comparison of flood vs. microlubrication on machining performance. Internet: http://www. unist. com/techsolve. html 2001.

7.Klocke, F.; Eisenblätter, G., Dry cutting. CIRP Annals-Manufacturing Technology 1997, 46 (2), 519526.

8.Wakabayashi, T.; Inasaki, I.; Suda, S., Tribological action and optimal performance: research activities regarding MQL machining fluids. Machining science and technology 2006, 10 (1), 59-85.

9.Attanasio, A.; Gelfi, M.; Giardini, C.; Remino, C., Minimal quantity lubrication in turning: Effect on tool wear. Wear 2006, 260 (3), 333-338.

10.Ronan, A.; Liang, S. Y.; George, W., Minimum Quantity Lubrication in Finish Hard Turning. HNICEM: 2003.

11.Varadarajan, A.; Philip, P.; Ramamoorthy, B., Investigations on hard turning with minimal cutting fluid application (HTMF) and its comparison with dry and wet turning. International Journal of Machine Tools and Manufacture 2002, 42 (2), 193-200.

12.Khan, M.; Mithu, M.; Dhar, N., Effects of minimum quantity lubrication on turning AISI 9310 alloy steel using vegetable oil-based cutting fluid. Journal of materials processing Technology 2009, 209 (15), 5573-5583.

13.Dhar, N.; Ahmed, M.; Islam, S., An experimental investigation on effect of minimum quantity lubrication in machining AISI 1040 steel. International Journal of Machine Tools and Manufacture 2007, 47 (5), 748-753.

14.Yan, L.; Yuan, S.; Liu, Q., Influence of minimum quantity lubrication parameters on tool wear and surface roughness in milling of forged steel. Chinese Journal of Mechanical Engineering 2012, 25 (3), 419429.

15.Hwang, Y.-K.; Lee, C.-M.; Park, S.-H., Evaluation of machinability according to the changes in machine tools and cooling lubrication environments and optimization of cutting conditions using Taguchi method. International Journal of Precision Engineering and Manufacturing 2009, 10 (3), 65-73. 